\title{
Options for management of municipal solid waste in New York City: A preliminary comparison of health risks and policy implications
}

\author{
Pearl Moy ${ }^{\mathrm{a}}$, Nikhil Krishnan ${ }^{\mathrm{b}}$, Priscilla Ulloa ${ }^{\mathrm{b}}$, Steven Cohen ${ }^{\mathrm{c}}$, Paul W. Brandt-Rauf ${ }^{\mathrm{a}, \mathrm{b}, *}$ \\ ${ }^{a}$ Department of Environmental Health Sciences, Mailman School of Public Health, Columbia University, 60 Haven Avenue, NY 10032, USA \\ ${ }^{\mathrm{b}}$ Department of Earth and Environmental Engineering, Fu Foundation School of Engineering and Applied Science, Columbia University, NY 10027, USA \\ ${ }^{\mathrm{c}}$ Program in Environmental Science and Policy, School of International and Public Affairs, Columbia University, NY 10027, USA
}

Received 24 December 2005; received in revised form 14 November 2006; accepted 4 January 2007

Available online 26 March 2007

\begin{abstract}
Landfill disposal and waste-to-energy (WTE) incineration remain the two principal options for managing municipal solid waste (MSW). One critical determinant of the acceptability of these options is the different health risks associated with each. In this analysis relying on published data and exposure modeling, we have performed health risk assessments for landfill disposal versus WTE treatment options for the management of New York City's MSW. These are based on the realistic scenario of using a waste transfer station (WTS) in Brooklyn and then transporting the untreated MSW by truck to a landfill in Pennsylvania or using a WTE facility in Brooklyn and then transporting the resultant ash by truck to a landfill in Pennsylvania. The overall results indicate that the individual cancer risks for both options would be considered generally acceptable, although the risk from landfilling is approximately 5 times greater than from WTE treatment; the individual non-cancer health risks for both options would be considered generally unacceptable, although once again the risk from landfilling is approximately 5 times greater than from WTE treatment. If one considers only the population in Brooklyn that would be directly affected by the siting of either a WTS or a WTE facility in their immediate neighborhood, individual cancer and non-cancer health risks for both options would be considered generally acceptable, but risks for the former remain considerably higher than for the latter. These results should be considered preliminary due to several limitations of this study such as: consideration of risks only from inhalation exposures; assumption that only volume and not composition of the waste stream is altered by WTE treatment; reliance on data from the literature rather than actual measurements of the sites considered, assuming comparability of the sites. However, the results of studies such as this, in conjunction with ecological, socioeconomic and equity considerations, should prove useful to environmental managers, regulators, policy makers, community representatives and other stakeholders in making sound and acceptable decisions regarding the optimal handling of MSW.
\end{abstract}

(C) 2007 Elsevier Ltd. All rights reserved.

Keywords: Municipal solid waste; Landfill disposal; Waste-to-energy incineration; Health risk assessment

\section{Introduction}

Despite increased efforts to prevent, reduce, reuse and recycle waste, the appropriate management of municipal solid waste (MSW) remains a major environmental issue (Landreth and Rebers, 1997; Williams, 2005). Currently,

\footnotetext{
*Corresponding author. Department of Environmental Health Sciences, Mailman School of Public Health, Columbia University, 60 Haven Avenue, NY 10032, USA. Tel.: + 12123053959 ; fax: +12123054012 .

E-mail address: pwb1@columbia.edu (P.W. Brandt-Rauf).
}

there are two principal options for managing such MSWlandfill disposal or incineration in waste-to-energy (WTE) facilities (Landreth and Rebers, 1997; Williams, 2005). However, concerns have been raised in the past that emissions from both landfills and incinerators may pose environmental health risks that make both options less than optimal (Rushton, 2003). Both of these technologies have been improved in the last 20 years. Modern landfills are required by Subtitle D rules (Lee et al., 2000) to include a non-permeable liner at the bottom, be capped at the top, and contain and treat emissions as much as possible (Landreth and Rebers, 1997; Williams, 2005). WTE 
facilities, through the implementation of EPA Maximum Achievable Control Technology (MACT) standards, have reduced emissions of certain hazardous materials including heavy metals and dioxins by a factor of almost 100 (Williams, 2005). Nevertheless, there is a continuing debate over which option, landfill disposal or WTE treatment, poses less risk to the environment and human health, the latter concern usually being the most important for affected populations (Rushton, 2003).

The present study is a preliminary attempt to quantify and compare the health risks from landfill disposal and WTE treatment using the principles of risk assessment. The study focuses on one hypothetical scenario of MSW management in New York City (NYC), which generates large amounts of MSW and is searching for more effective methods for its handling. NYC currently exports most of its MSW to out-of-state landfills that are constrained by decreasing capacity and thus charge increasing tipping fees (Tammemagi, 1999). On the other hand, there is considerable community resistance to siting a WTE facility in NYC due in large part to concerns over associated potential health risks (Tammemagi, 1999). Therefore, a comparison of the health risks for these two options could be useful for environmental managers, regulators and policy makers, as well as other concerned stakeholders including the affected communities, in terms of reaching consensus regarding the most acceptable option for the future handling of MSW.

\section{Methods}

The objective of this study was to use risk assessment methodology (NRC, 1994) to estimate and compare the human health impacts of inhalation exposure from emissions from landfill disposal and WTE treatment of managing one million tons of MSW in 1 year in NYC. Based on the literature (Landreth and Rebers, 1997; Rushton, 2003; Williams, 2005), it was assumed that inhalation represents the most significant route of exposure; although indirect pathways of exposure are know to exist, they could not be adequately considered in this study due to a lack of relevant data on the sites.

The study thus considered two specific options: (1) siting of a waste transfer station (WTS) in Greenpoint, Brooklyn, for collection of MSW with transportation via diesel trucks to final disposal in a landfill in Dunmore, PA; or (2) siting a WTE facility in Greenpoint, Brooklyn, for combustion and electricity generation, with transportation via diesel trucks for the resultant ash to final disposal in a landfill in Dunmore, PA (see Fig. 1). The first option represents the predominant method of MSW disposal in NYC. Currently, $71 \%$ of all of NYC's MSW and all of Brooklyn's MSW is transported via trucks to landfill disposal in $\mathrm{PA}, \mathrm{OH}$ or VA (Tammemagi, 1999). The second option has the advantage of reducing the volume of the waste stream that requires landfill disposal by up to $90 \%$ (Tammemagi, 1999); in this study, we assumed a relatively conservative reduction of the volume of MSW by $80 \%$ using the WTE option.

\subsection{WTS scenario}

Greenpoint, Brooklyn, was chosen as the particular site for facility placement because it represents a typical mixeduse municipal neighborhood containing multiple industrial facilities and residential dwellings. More importantly, it has been considered by the city as a potential location for a large marine WTS that could handle this scale of MSW volume; in anticipation of such a siting, the NYC Department of Sanitation has recently prepared an environmental impact statement for this facility which includes an assessment of the hazardous exposures and estimated resultant health risks associated with the facility which we could use for direct comparison to the risks associated with a WTE facility at the same site (NYC DOS, 2005). This is one of the few, if not only, health-risk assessments for a WTS available in the literature. This study estimated typical exposures to pertinent hazardous agents from a WTS (benzene, formaldehyde, 1,3-butadiene, acetaldehyde, benzo(a)pyrene, propylene, acrolein, toluene, xylenes, anthracene, benzo(a)anthracene, chrysene, naphthylene, pyrene, phenanthrene, dibenz(a,h)anthracene) and used accepted unit cancer and non-cancer risk factors for each to calculate individual cancer and acute and chronic non-cancer health risks (NYC DOS, 2005). Thus, the individual cancer risk and the sum of the individual acute and chronic non-cancer risk values from this report were used directly in this study in combination with similar risk values for landfilling (from the literature as described below) and truck transportation (calculated as described below) in the evaluation of the first option.

\subsection{Landfilling scenario}

Although no health-risk assessments specific to landfill facilities for NYC MSW such as the one in Dunmore, PA, have been performed, health-risk assessments have been performed previously for typical modern MSW landfill facilities that include impermeable liners, leachate collection and gas emission collection for power generation. A study by Manca et al. (1997) was chosen for use in this case because of similarities to the Dunmore site in terms of the technology employed, environmental conditions and receptor distribution. This study estimated typical exposures from pertinent hazardous agents from a landfill facility (1,1-dichloroethane, vinyl chloride, bromodichloromethane, 1,1-dichloroethylene, 1,1,2,2-tetrachloroethane, methylene chloride, trichloroethylene, 1,2-dichloroethane, 1,1,2-trichloroethane, chloroethane, benzene, methyl mercaptan, ethyl mercaptan, hydrogen sulfide, iron, zinc, lead) and used accepted cancer and non-cancer unit risk factors for each to calculate individual cancer and non-cancer health risks (Manca et al., 1997). Thus, the individual cancer and non-cancer risk values from this study were used in the present study, adjusted for the difference in waste volume between the two studies (6.6 versus 1.0 million tons for the Manca study and our study, 


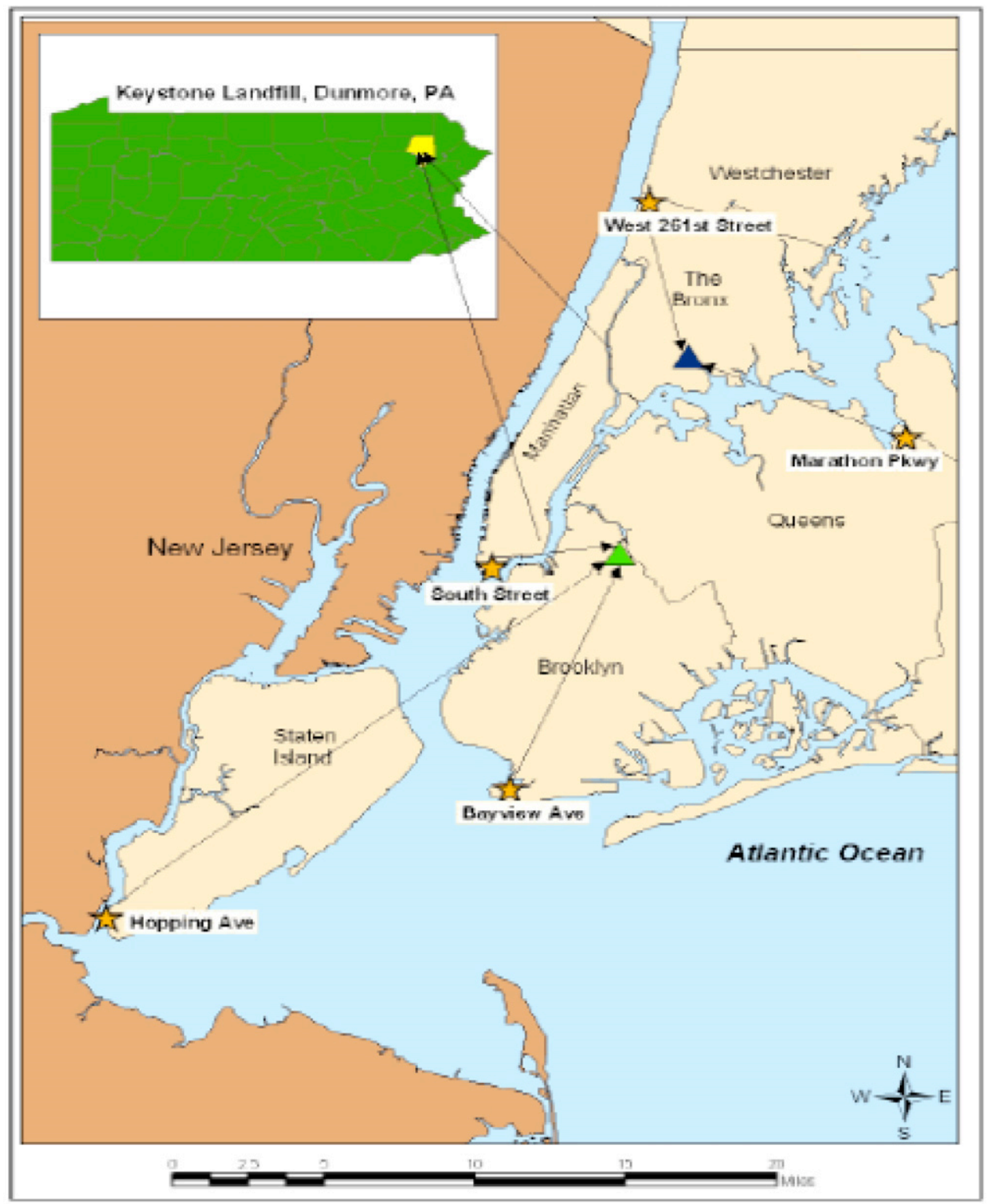

Fig. 1. Map illustrating the siting of a WTS or WTE facility at Greenpoint, Brooklyn (center triangle) in New York City and a landfilling facility in Dunmore, PA (inset) for disposal of MSW or WTE ash (adapted from DeAngelo, 2004).

respectively), in combination with similar risk values for a WTS (as described above) and truck transportation (as described below) in the evaluation of the first option. In addition, similar cancer and non-cancer risk values were used in the present study, adjusted for the difference in waste volume reduction for WTE treatment (as noted above, assumed to be $80 \%$ ), in combination with similar risk values for WTE (calculated as described below) and truck transportation (as described below) in the evaluation of the second option. In this case, an additional assumption was made that only the volume, not the nature of the hazardous components, of the MSW was altered by the WTE treatment; this is clearly an over-simplification because in some cases, e.g., embedding of the ash in lime would raise the $\mathrm{pH}$ and inhibit metal contaminant mobility. Thus, one might expect the total concentration of hazardous materials to vary somewhat after WTE treatment, but these potential changes were ignored in this first approximation due to a lack of relevant data. It should be noted that these changes would likely decrease the risks associated with landfilling ash so that not taking this into account represents a worst case scenario, providing an upper bound on the associated risks.

\subsection{Truck transport scenario}

One of the current sites for landfill disposal for NYC MSW is in Dunmore, PA, approximately 190 miles from Greenpoint. A box model incorporating vertical and horizontal dispersion and wind speed was used to estimate the exposures and resultant health impacts from diesel truck transport of the MSW or WTE ash (estimating 20 ton 
transported per truck) over this route (Derwent et al., 1995). The model assumes a uniform distribution of emission of pollutants along the route with vertical and horizontal dispersions of 1000 and $3000 \mathrm{~m}$, respectively, chosen based on estimates from studies of mixing depths over the northeastern USA (Berman et al., 1999). Average wind speed for NY, NJ and PA was obtained from the 1996 Wind Energy Resource Atlas of the USA (NREL, 1996). The diesel pollutants of major concern were considered to be nitrogen oxides $\left(\mathrm{NO}_{x}\right)$ and particulate matter (PM) with emission rates based on 1998 EPA emissions standards for new trucks (US EPA, 2002). Ground level exposure concentrations for $\mathrm{NO}_{x}$ and $\mathrm{PM}$ were calculated from these emission rates applied to the box model, and average annual concentrations were converted to individual cancer and non-cancer health-risk values through multiplication by unit cancer (for PM) and non-cancer (for $\mathrm{NO}_{x}$ and $\mathrm{PM}$ ) risk factors taken from the published literature (CA OEHHA, 2005; US EPA, 2005).

\subsection{WTE scenario}

For the WTE facility, major pollutants of concern were considered to be: dioxins and related compounds (combined as TEQ), mercury, cadmium, lead, $\mathrm{PM}, \mathrm{HCl}, \mathrm{SO}_{2}$ and $\mathrm{NO}_{x}$ (NRC, 2000; Rushton, 2003). Emission factors for each were taken from the EPA Performance Data for Large Municipal Waste Combustors at MACT (US EPA, 2000) to generate emission rates for 1 million tons MSW processed. These emission rates, along with typical WTE facility characteristics (e.g., a stack height of $85 \mathrm{~m}$ )(EBI USA, 2005), were used to calculate ground level concentrations using a standard Gaussian plume air dispersion model (Boudet et al., 1999) with reflection, using the McElroy-Pooler values and incorporating wind rose data (speed, direction and temperature) for nearby LaGuardia airport from the National Climate Data Center and NOAA, in $100 \mathrm{~m}^{2}$ grids around the WTE facility (Wark et al., 1998; NOAA, 2005). Average annual concentrations for each pollutant were converted to individual cancer and non-cancer risk values through multiplication by unit cancer and non-cancer risk factors taken from the published literature (US EPA, 1997, 2005; CA OEHHA, 2005).

For each specific step above (WTS, landfill of untreated MSW or ash, transport of untreated MSW or ash, WTE), individual cancer and non-cancer risk values for each pollutant of concern were summed to yield total individual cancer and non-cancer risk values. Then, for each treatment option (WTS/untreated MSW transport/landfill or WTE/ash transport/landfill), total individual cancer and non-cancer health risks were calculated and compared.

\section{Results}

The individual cancer and non-cancer health risks for each specific step (WTS, landfill of untreated MSW or ash, transport of untreated MSW or ash, WTE) are presented in Table 1. Acceptable excess cancer risks for the general population are usually considered to be less than one excess cancer case per $10,000-1,000,000$ people $(1.0 \mathrm{E}-04$ to 1.0E-06)(NRC, 1994). For the steps of WTS, untreated MSW transport, ash transport, and WTE, the excess cancer risks are well below this range, and for untreated MSW landfill and ash landfill, they are still well within this acceptable range. Acceptable non-cancer risks are usually considered to have a Hazard Quotient less than 1.0 (i.e., Chronic Daily Intake is less than the Reference Dose, which is defined as that chronic dose that is unlikely to result in deleterious health effects with an adequate margin of safety) (NRC, 1994). Once again, for the steps of WTS, untreated MSW transport, ash transport, and WTE, the non-cancer risks are well below this value. However, in this case, the untreated MSW landfill and ash landfill are above this value, and the former is well above.

The total individual cancer and non-cancer health risks for each treatment option (WTS/untreated MSW transport/untreated MSW landfill or WTE/ash transport/ash landfill) derived by summing the appropriate items from Table 1 are presented and compared in Table 2. For the both options, the individual cancer risk is within the acceptable range ( $4.0 \mathrm{E}-05$ and $7.9 \mathrm{E}-06$, respectively), but the individual non-cancer risk is well above the acceptable

Table 1

Individual health risks associated with various handling methods for NYC $\mathrm{MSW}^{\mathrm{a}}$

\begin{tabular}{llll}
\hline Method & & $\begin{array}{l}\text { Individual } \\
\text { cancer risk }\end{array}$ & $\begin{array}{l}\text { Individual non- } \\
\text { cancer risk }\end{array}$ \\
\hline WTS in Brooklyn & & $1.3 \mathrm{E}-07$ & $4.6 \mathrm{E}-01$ \\
Transport to PA & Untreated & $3.9 \mathrm{E}-07$ & $5.2 \mathrm{E}-04$ \\
Landfill & MSW & & \\
& WTE Ash & $7.8 \mathrm{E}-08$ & $1.0 \mathrm{E}-04$ \\
Landfilling in PA & Untreated & $3.9 \mathrm{E}-05$ & $1.2 \mathrm{E}+01$ \\
& $\begin{array}{l}\text { MSW } \\
\text { WTE Ash }\end{array}$ & $7.8 \mathrm{E}-06$ & $2.3 \mathrm{E}+00$ \\
WTE in Brooklyn & & $6.6 \mathrm{E}-08$ & $6.3 \mathrm{E}-04$ \\
\hline
\end{tabular}

${ }^{\mathrm{a}}$ Based on handling one million tons of MSW in 1 year.

Table 2

Comparison of individual health risks associated with landfill disposal versus WTE treatment for NYC MSW

\begin{tabular}{lll}
\hline Option & Individual cancer risk & $\begin{array}{l}\text { Individual non- } \\
\text { cancer risk }\end{array}$ \\
\hline Landfill disposal & $4.0 \mathrm{E}-05$ & $1.2 \mathrm{E}+01$ \\
WTE treatment & $7.9 \mathrm{E}-06$ & $2.3 \mathrm{E}+00$ \\
Ratio of landfill & 5.0 & 5.2 \\
disposal risk/WTE & & \\
treatment risk & & \\
\hline
\end{tabular}

${ }^{\mathrm{a}}$ Based on handling one million tons of MSW in 1 year. 
value of $1.0 \quad(1.2 \mathrm{E}+01$ and $2.3 \mathrm{E}+00$, respectively). However, for both individual cancer and non-cancer risks, the first option yields risks that are higher than the second option, approximately by a factor of 5 (5.0 for cancer risk and 5.2 for non-cancer risk).

\section{Discussion and conclusions}

Based strictly on the outcome of the health-risk assessments, one would conclude that WTE treatment is a better option than landfilling for NYC MSW due to the differences in non-cancer and cancer health risks noted above. Furthermore, it should be noted that more expensive technology currently exists (and is mandated for use to meet the more stringent European Union emissions standards) that would make the WTE emissions even lower, thus further favoring this option from a health risk perspective.

However, the limitations of this study should be kept in mind. First, the landfill risk estimates were not based on a NYC landfill but were based on literature estimates of typical municipal landfill chemicals of concern, although the particular study chosen is similar to others in the literature (as described below) and there is no reason to assume that a NYC landfill would differ significantly from these. Second, the box model used for truck transport exposures is relatively simple and does not incorporate the impact of meteorological conditions (other than wind) and terrain type which could alter the exposures to pollutants. In addition, many NYC landfill sites are farther away than Dunmore, PA, so exposed populations at risk could be larger. Conversely, as diesel truck fleets for transport of untreated MSW or WTE ash age and are replaced by trucks that meet more stringent 2004 emissions standards, the corresponding exposures and health risks should decrease. As noted, we have used a relatively conservative assumption of only $80 \%$ reduction in waste volume from WTE treatment. Larger reductions in volume from WTE treatment, which are clearly achievable with state-of-theart facilities (Landreth and Rebers, 1997; Williams, 2005), would result in even bigger differences between the two MSW management options, further favoring the second option. Also, as noted, it is likely that WTE treatment would alter not only the volume of waste but also the composition of the waste to be landfilled, and this may conceivably result in even lower health risks from landfilling WTE ash compared to untreated MSW (Landreth and Rebers, 1997; Williams, 2005), again further favoring the second option. The health-risk assessment for the WTS was based on a study for a proposed marine WTS, which would involve less truck traffic, at least in the immediate vicinity, and alteration in the transportation-associated risks because subsequent truck-based transport routes would be different. Finally, other plume dispersion models are available (Derwent et al., 1995) that might provide different, and perhaps better, estimates of exposures and risks from a WTE facility.
Nevertheless, despite the uncertainties and assumptions involved in this study, the results are in reasonable agreement with those from other studies in the literature. For example, a health-risk assessment of a WTE facility in Montgomery County, MD, with a similar pollution emission profile, estimated cancer risks ranging from $1.07 \mathrm{E}-07$ to $2.41 \mathrm{E}-08$ based on actual emissions data, compared to a cancer risk of $6.55 \mathrm{E}-08$ in this study, which is right in the middle of this range (Rao et al., 2003). As noted above, health-risk values from other landfill studies also agree reasonably with those used for this study (e.g., a cancer risk of $2.0 \mathrm{E}-05$ compared to $4.0 \mathrm{E}-05$ here) (Redfearn and Roberts, 2002). Eschenroeder and von Stackelberg (1999) compared the health risks from landfills and WTE facilities and found cancer risks for the former of $1.1 \mathrm{E}-05$ and for the latter of $4.0 \mathrm{E}-06$, similar to those from this study. Finally, a study by the Ontario Ministry of the Environment (1999) estimated cancer risks ranging from $4.0 \mathrm{E}-06$ to $1.0 \mathrm{E}-05$ for landfills and $4.7 \mathrm{E}-08$ to 2.3E-07 for WTE facilities, similar to those from this study. Therefore, although this study cannot be considered definitive in terms of the health risks for landfill or WTE facilities, its results are consistent with others and thus plausible.

However, it must also be recognized that the cancer and non-cancer disease risks in this study are distributed across different populations (those around the landfill, those along the truck route, and those around the WTS or WTE facility). A more critical issue for environmental managers, regulators, policy makers and community representatives in NYC could be the difference in health risks posed only by siting a WTS as opposed to a WTE facility to the population in their immediate neighborhood. Even by this comparison, a WTS is a less healthy option than a WTE facility for the neighboring population, although for both the risks are within acceptable limits. For example, the individual non-cancer risk from a WTS $(4.6 \mathrm{E}-01)$ is 727 times higher than that from a WTE facility $(6.3 \mathrm{E}-04)$, and the individual cancer risk from a WTS $(1.3 \mathrm{E}-07)$ is 2 times higher than that from a WTE facility $(6.6 \mathrm{E}-08)$, in this population.

Given the limitations of the current study noted above, it is still possible that these results alone are insufficient for making decisions on MSW handling options that are acceptable to all stakeholders. Additional studies of this nature, however, can be used to help further refine the decision-making process. Future studies could address the limitations of the current study, for example, by using different dispersion models, multi-compartment and/or scenario analyses, inclusion of secondary pathways of exposure to pollutants, emissions data from actual facilities, sensitivity analyses that vary the parameters of the models, and statistical uncertainty analyses such as Monte Carlo methods for better quantification of the range of uncertainties in the risk estimates, among others. Finally, innovative approaches to health risk assessment based on molecular epidemiologic methods could incorporate 
biomarker measurements as estimates of the actual absorbed doses of pollutants of concern from these facilities in exposed populations. For example, in previous studies of workers at NYC's former MSW incinerators, we were able to identify elevated levels of biomarkers for metal (lead) and organic (dioxins) contaminants of incinerator ash in some individuals (Schecter et al., 1991; Malkin et al., 1992); more recent studies have followed up on this approach and confirmed elevated levels of dioxins in incinerator workers in other countries (Kumagai and Koda, 2005; Shih et al., 2006). Although it should be recognized that emissions for lead and dioxins have likely decreased in recent years (Chang and Lin, 2001; Chang et al., 2001; Domingo et al., 2001; Meneses et al., 2004), applying similar approaches for measuring biomarkers in exposed populations around current stateof-the-art facilities may still be useful in providing more persuasive evidence for (or against) the choice of particular options for MSW management based on health considerations (Gonzalez et al., 2000). For example, it would be useful to recruit a population in Greenpoint now before a facility is sited there and measure the relevant biomarkers and then again after the facility is in operation; this could help define more precisely the contaminant burden due to the facility as opposed to other confounding sources.

In the final analysis, though, such health considerations will be only one, albeit an important one, of the considerations of environmental managers, regulators, policy makers, community representatives and other stakeholders must take into account in choosing options for MSW handling. Ecological impact on non-human populations may be a significant concern in certain situations. Broader economic and social impacts and considerations of environmental justice and equity will also remain central issues in any future decision-making on MSW management. Thus, as has been discussed in detail elsewhere, the issue of NYC's MSW has multiple dimensions, including ethical, political, technological, policy and managerial elements (Cohen, 2006). However, progress to date has been stymied primarily because the politics of siting of MSW facilities, particularly "not-in-my-backyard" self-interest politics, tends to dominate the other aspects. Therefore, it is unlikely that a resolution of NYC's MSW problems will be forthcoming in the absence of considerable community-based environmental education efforts. As out-of-state landfill options become more restricted and their tipping fees increase further, such educational efforts will be useful as communities are forced to face the trade-offs of the various MSW management options, such as hosting a WTS versus a WTE facility (Cohen, 2006). Scientific considerations, such as the comparative health risk assessment presented here, will need to be part of these educational efforts so that they can play a meaningful role in influencing the political dialogue in arriving at solutions for the optimal handling of MSW in NYC and elsewhere.

\section{Acknowledgments}

This work was supported in part by funding from the Waste-to-Energy Research and Technology Council to Prof. N. Themelis and the Earth Engineering Center and by funding from NIEHS (P30-ES09089).

\section{References}

Berman, S., Ku, J.Y., Rao, S.T., 1999. Spatial and temporal variation in the mixing depth over the Northeastern United States during the summer of 1995. Journal of Applied Meteorology 38, 1661-1673.

Boudet, C., Zmirou, D., Laffond, M., Balducci, F., Benoit-Guyod, J.L., 1999. Health risk assessment of a modern municipal waste incinerator. Risk Analysis 19, 1215-1232.

CA OEHHA, 2005. Toxicity Criteria Database. California Office of Environmental Health Hazard Assessment, Sacramento.

Chang, M.B., Lin, J.J., 2001. Memory effect on the dioxin emissions from municipal waste incinerator in Taiwan. Chemosphere 45, 1151-1157.

Chang, B.C., Wey, M.Y., Huang, S.M., 2001. Heat treatment of incinerator retired sorbents containing heavy metals. Science of the Total Environment 273, 83-92.

Cohen, S., 2006. Understanding Environmental Policy. Columbia University Press, New York.

DeAngelo, M., 2004. Siting of waste-to-energy facilities in New York City using GIS technology. Master of Science Thesis, Department of Earth and Environmental Engineering, Columbia University, New York. Available online at http://www.seas.columbia.edu/earth/wtert/sofos/ DeAngelo_Thesis_final.pdf.

Derwent, R.G., Mid̄̄leton, D.R., Field, R.A., Goldstone, M.E., Lester, J.N., Perry, R., 1995. Analysis and interpretation of air quality data from an urban roadside location in Central London over the period from July 1991 to July 1992. Atmospheric Environment 29, 923-946.

Domingo, J.L., Schuhmacher, M., Llobet, J.M., Muller, L., Rivera, J., 2001. PCDD/F concentrations in soil and vegetation in the vicinity of a municipal waste incinerator after a pronounced decrease in the emissions of PCDD/Fs from the facility. Chemosphere 43, 217-226.

EBI USA, 2005. The Directory of Waste-to-Energy Facilities. Environmental Business International, San Diego.

Eschenroeder, A., von Stackelberg, K., 1999. Health risks of landfilling versus combustion of municipal solid waste: an Illinois comparison. Proceedings of Air and Waste Management Association 99-57, 1-16.

Gonzalez, C.A., Kogevinas, M., Gadea, E., Huici, A., Bosch, A., Bleda, M.J., Papke, O., 2000. Biomonitoring study of people living near and working at a municipal solid-waste incinerator before and after two years of operation. Archives of Environmental Health 55, 259-267.

Kumagai, S., Koda, S., 2005. Polychlorinated dibenzo-p-dioxin and dibenzofuran concentrations in serum samples of workers at an infectious waste incinerator plant in Japan. Journal of Occupational and Environmental Hygiene 2, 120-125.

Landreth, R.E., Rebers, P.A., 1997. Municipal Solid Waste: Problems and Solutions. CRC Press, Boca Raton.

Lee, C.C., Huffmann, G.L., Mao, Y.L., 2000. Regulatory framework for the thermal treatment of various waste streams. Journal of Hazardous Materials 76, 13-22.

Malkin, R., Brandt-Rauf, P., Graziano, J., Parides, M., 1992. Blood lead levels in incinerator workers. Environmental Research 59, 265-270.

Manca, D., Birmingham, B., Raha, D., 1997. Toxicological screening of chemical emissions from municipal solid waste landfills: application of a predictive framework to a state-of-the-art facility. Human and Ecological Risk Assessment 3, 257-286.

Meneses, M., Schuhmacher, M., Domingo, J.L., 2004. Health risk assessment of emissions of dioxins and furans from a municipal waste incinerator: comparison with other emission sources. Environment International 30, 481-489. 
NOAA - National Oceanic and Atmospheric Administration, 2005. Climate Report for NY LaGuardia Airport. US Department of Commerce, Washington, DC.

NRC - National Research Council, 1994. Science and Judgment in Risk Assessment. National Academy Press, Washington, DC.

NRC - National Research Council, 2000. Waste Incineration and Public Health. National Academy Press, Washington, DC.

NREL - National Renewable Energy Laboratory, 1996. Wind Energy Resource Atlas of the United States. US Department of Energy, Washington, DC.

NYC DOS-New York City Department of Sanitation, 2005. Final Environmental Impact Statement (FEIS) for the New York City Comprehensive Solid Waste Management Plan. Bureau of Public Information and Community Affairs, New York.

Ontario Ministry of the Environment, Standards Development Branch, Environmental Sciences and Standards Division, 1999. Environmental Risks of Municipal Non-Hazardous Waste Landfilling and Incineration. Queen's Printer for Ontario, Toronto.

Rao, R.K., Chaudhuri, I., Garcia, M., Stormwind, B., Ruffle, B., 2003. Multiple pathway health risk assessment of a municipal waste resource recovery facility in Maryland. EM. August 21-26.

Redfearn, A., Roberts, D., 2002. Health effects and landfill sites. Issues of Environmental Science and Technology 18, 103-140.
Rushton, L., 2003. Health hazards and waste management. British Medical Bulletin 68, 183-197.

Schecter, A.J., Malkin, R., Papke, O., Ball, M., Brandt-Rauf, P.W., 1991. Dioxin levels in blood of municipal incinerator workers. Medical Science Research 19, 331-332.

Shih, T.S., Chen, H.L., Wu, Y.L., Lin, Y.C., Lee, C.C., 2006. Exposure assessment of polychlorinated dibenzo-p-dioxins and dibenzofurans $(\mathrm{PCDD} / \mathrm{Fs})$ in temporary municipal-waste-incinerator maintenance workers before and after annual maintenance. Chemosphere 64, 1444-1449.

Tammemagi, H.Y., 1999. The Waste Crisis: Landfills, Incinerators and the Search for a Sustainable Future. Oxford University Press, New York.

US EPA, 1997. Health Effects Assessment Summary Table. US Environmental Protection Agency, Washington DC

US EPA, 2000. Performance Data for Large MWC at MACT. US Environmental Protection Agency, Washington DC.

US EPA, 2002. Diesel Exhaust in the United States. US Environmental Protection Agency, Washington DC.

US EPA, 2005. Integrated Risk Information System (IRIS). US Environmental Protection Agency, Washington, DC.

Wark, K., Warner, C.F., Davis, W., 1998. Air Pollution: Its Origin and Control, third ed. Addison Wesley, San Francisco.

Williams, P.T., 2005. Waste Treatment and Disposal, second ed. Wiley, Chichester. 